\title{
Addressing sexual and gender-based violence (SGBV) against adolescent girls
}

Sajeda Amin

Population Council

Althea D. Anderson

Population Council

Follow this and additional works at: https://knowledgecommons.popcouncil.org/departments_sbsr-pgy

Part of the Demography, Population, and Ecology Commons, Domestic and Intimate Partner Violence Commons, Family, Life Course, and Society Commons, Gender and Sexuality Commons, International

Public Health Commons, and the Medicine and Health Commons

How does access to this work benefit you? Let us know!

\section{Recommended Citation}

Amin, Sajeda and Althea D. Anderson. 2011. "Addressing sexual and gender-based violence (SGBV) against adolescent girls," Promoting Healthy, Safe, and Productive Transitions to Adulthood Brief no. 38. New York: Population Council. 


\title{
Addressing sexual and gender-based violence (SGBV) against adolescent girls
}

\author{
Prepared by Sajeda Amin and Althea D. Anderson
}

$\mathrm{T}$ -he Population Council's extensive work on adolescent safe spaces and livelihoods programs has demonstrated the pathways of empowering adolescent girls and the substantial benefits for society (Levine et al. 2009; Mensch, Bruce, and Greene 1998; Chong, Hallman, and Brady 2006). Monitoring and evaluation data from these initiatives have produced empirical evidence about numerous threats to girls' health and well-being that relate to both long-standing and emergent social forces. Some long-standing practices such as exclusion of women from labor markets or the early marriage of girls to older men contribute to gender power inequalities that are at the root of genderbased violence. Meanwhile, positive shifts in social and economic conditions that have increased girls' educational attainment and participation in formal labor markets have also had unforeseen negative effects on gender power dynamics. These include increases in girls' involvement in transactional sex in exchange for grades and school expenses, as well as vulnerability to sexual exploitation by employers in the workforce. In developing countries, where the risk of adverse sexual and reproductive health outcomes is high and young girls are at particularly high risk, it is important to address issues related to sexual and gender-based violence (SGBV) and gender norms that relate to these risks.

The majority of programs addressing sexual and gender-based violence are focused on providing clinical health services or legal services. Programmatic interventions for the prevention of violence rely on correlational studies to identify high risks such as poverty, urban living, poor education, sexually transmitted diseases, and attitudinal factors such as community acceptance of violence against women. These programmatic approaches seek to reduce violence either by targeted strategies or by broad approaches to delegitimize violent behaviors. Theoretical studies on SGBV emphasize women's economic disempowerment, women's dependence on men, and patriarchal social structures that privilege men in other ways. While these studies help us to understand factors that perpetuate violence, a clearly articulated theory of attitude and behavior change is often lacking in violence prevention programs.

Interventions to eliminate SGBV incorporating community-based approaches have been pioneered by Jewkes and colleagues through-

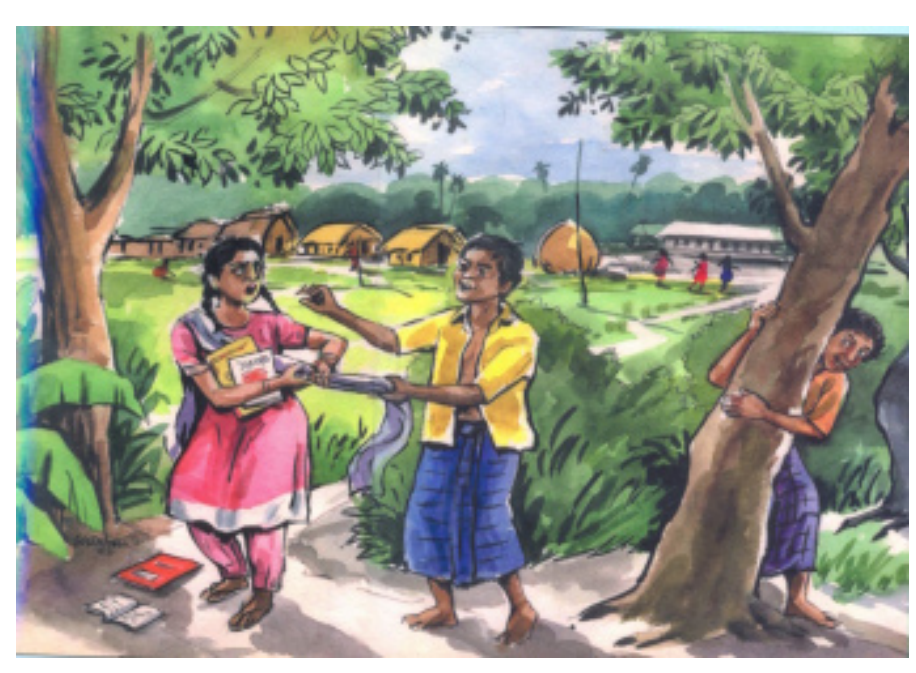

out southern Africa. Their research points to the importance of gender power inequalities, status within male peer groups, and patterns of male sexual entitlement in dominant social constructions of masculinity as determinants of SGBV (Wood and Jewkes 2001; Jewkes et al. 2009).

The evidence indicates that girls are rendered most vulnerable due to a combination of dominant gender and age hierarchies that severely hinder girls' ability to refuse male sexual advances (Jewkes, Penn-Kekana, and Rose-Junius 2005). The Population Council's work with adolescents reinforces the importance of multiple points of entry to change community norms regarding SGBV. While it is essential to work with girls and women to empower them and to build their assets, it is not sufficient if the community is not also engaged.

\section{Focus on Adolescent Girls}

The Council has undertaken programmatic research on adolescent girls' life skills and livelihoods initiatives that could also inform a more holistic approach to addressing SGBV. Our focus on young girls stems from the fact that adolescence is a critical moment when women's vulnerability is consolidated. The experiences of female genital cutting, forced sex, be- 
coming HIV infected, child marriage, and childbearing during childhood can have both immediate and lifelong repercussions. Girls who are the most vulnerable in society, including those who are poor, orphaned, and socially isolated, are usually at highest risk. Evidence from the Council's adolescent girls programming, seeking to reduce vulnerability during this crucial period, is potentially useful in creating innovative interventions to address SGBV. Toward this goal we are initiating the following activities:

1. Gleaning lessons from our work on improving the health sector's ability to respond to sexual violence;

2. Analyzing harmful traditional practices such as early marriage and female genital cutting for a better contextual understanding of gender-based violence;

3. Extracting lessons learned from our "safe spaces" and social exclusion work with adolescent girls to understand their personal assessments of vulnerability and coping strategies with regard to SGBV;

4. Drawing on programmatic interventions with men and boys to change gender norms and promote healthier forms of masculinity as a primary approach to make communities and relationships safer.

\section{Approaches to Addressing SGBV}

The provision of health and legal services for victims of violence has been the focus of programmatic efforts to address SGBV in much of the world. However, several studies show that reported cases of sexual assault account for only a small proportion of the true incidence of SGBV (Heise, Ellsberg, and Gottmoeller 2002; Jewkes and Abrahams 2002; Koss, Heise, and Russo 1994; WHO 2005). Moreover, most prevention programs that are offered in conjunction with service programs reach women who have been victims of SGVB. While they may address ways to prevent future occurrences for those individuals, there is a need for work that addresses primary prevention by changing the circumstances that support SGBV.

A repeated finding from health-sector reports is that the majority of people seeking services after sexual violence are girls, yet most programs and protocols within the health sector are designed for adults (Keesbury and Askew 2010). Young girls may be at increased risk of experiencing underreported forms of sexual violence, including unwanted and coerced sex and sexual exploitation.

An exclusive health sector/judicial approach focused on retribution and services for victims, while providing remedy for the physical and mental health outcomes of SGBV, lacks primary prevention measures. There is a need to identify the root causes of violence in order to design more appropriate points of intervention. A more comprehensive approach to addressing SGBV would include building economic and social assets for girls, while engaging men and boys in promoting healthier gender norms and working with communities to create safer environments. Such an approach has the added advantage that it may help to prevent or delay child marriage, which is increasingly recognized as a form of gender-based violence.

To identify an approach to SGBV prevention, the Council has reviewed its adolescent girls programming strategies and outcomes. The review shows that SGBV is a key concern and an important contextual

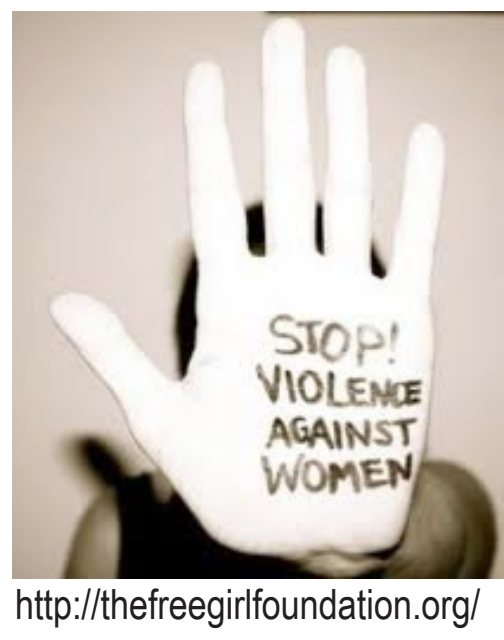

factor shaping our approach to working with girls. There is a strong demand from program implementers and beneficiaries for curricula and strategies to address SGBV in life-skills and livelihoods programs. These can include programmatic components that incorporate strategies to reduce social isolation and promote inclusion of girls, and strategies to engage men and boys to make society safe for girls.

In response to the growing awareness of the links between SGBV, health, human rights, and national development, the Population Council, with support from the Swedish-Norwegian Regional HIV and AIDS Team for Africa, initiated a multi-country SGBV network in 2006. This network includes eight partner agencies in East and Southern Africa that are implementing projects addressing the determinants and consequences of SGBV in an integrated manner. These agencies are strengthening national programmes to better meet the medical, psychological, and judicial needs of survivors of SGBV, while also enhancing strategies for its prevention (Population Council 2008).

\section{Building Social Assets}

Our "safe spaces" interventions offer several pathways to address SGBV through primary prevention strategies. Safe spaces provide the opportunity for girls to build social and human assets and increase access to social networks in physically safe spaces. Within these spaces, girls are able to foster social connections that contribute to risk reduction through group affiliation and identity, which enhances negotiation and communication skills and generates self-confidence (Austrian 2011; Austrian and Ghati 2010).

The Council's investment in creating access to safe spaces is driven by our work to address adolescent girls' social exclusion. In South Africa, for instance, Council researchers have studied the effects of personal insecurity on the daily lives of young men and women. The Council and the Crime Reduction in Schools Project (CRISP) conducted focus group workshops with youth living outside Durban, South Africa to map important spaces in their communities and then rate these spaces in terms of their safety. Findings indicate that girls identified far more physical dangers than boys, many of them associated with the risk of sexual assault and rape. Additionally, young girls (ages 10-13) were the most vulnerable and could not identify a single place in their communities that they recognized as more than "somewhat safe" (Kenworthy, Hall- 
man, and Diers 2008). Our research on social exclusion in South Africa demonstrates that adolescent girls have restricted access to social networks. Typically, adolescence is a time when young adults expand their geographic and intellectual horizons; however, for vulnerable girls social connections and access to community resources narrow considerably during this period. Our findings from South Africa show that social isolation is associated with girls' risk of experiencing sexual violence (see Figure 1).

In the Kibera neighborhood of Nairobi, Kenya, the Council's research has highlighted adolescents' experiences of violence as it relates to a lack of safe spaces. In a 2006 population-based study of adolescents in the Kibera slum, young people indicated that they had witnessed and experienced considerable violence and threats to safety, with many-especially girls-having limited support networks or safety nets. Adolescent girls, in particular, experience violence, molestation, coercion, and rape. Forty-three percent of girls had experienced coerced or forced first sex. Additionally, married adolescent girls reported high rates of domestic violence (Erulkar and Matheka 2007). An intervention seeking to address violence is the Binti Pamoja Center, a program for adolescent girls ages 10-22 in Kibera. Binti Pamoja provides girls with safe spaces and mentors through which they are able to learn about sexual and reproductive health, adolescent development, and financial education, and develop friendships and skills in communication, negotiation, and leadership. These programs offer critical activities that address health concerns and provide social and economic empowerment for girls. The Council has partnered with Binti Pamoja and other local NGOs to design skill-building programs and to monitor and evaluate their effect on strengthening economic and social assets and opportunities for girls in Kibera (Austrian 2011).

\section{Securing Economic Assets}

Adolescent girls' experiences of SGBV have also informed programmatic strategies to instill financial literacy and livelihood skills that are delivered in the context of safe spaces. In Bangladesh, the Council collaborated with the Bangladesh Institute of Development Studies to evaluate Kishori Abhijan (Adolescent Girls' Adventure), a livelihoods program modeled on the safe spaces framework. The program significantly increased girls' employment opportunities and health knowledge. For younger girls (aged 12-14) in the poorest district, the program contributed to improved school enrollment rates and lower marriage rates (Amin and Suran 2005). Researchers also found that Kishori Abhijan participants had formed a stronger sense of self-worth and connectedness when compared to girls who were not exposed to the intervention. Girls in the program were more likely to report having friends in the same village and had greater social mobility (Amin 2007). Council researchers also implemented financial education and savings programs in Kenya and Uganda, and financial literacy programs in South Africa (Austrian 2011; Hallman 2011).

\section{Future Directions}

Working with men and boys

While initiatives for girls are critical, their empowerment and advancement are ultimately contingent on the transformation of community
Figure 1. Girls with fewer social connections are more likely to experience forced sex (Ever been physically forced: 14-16-year-old females)

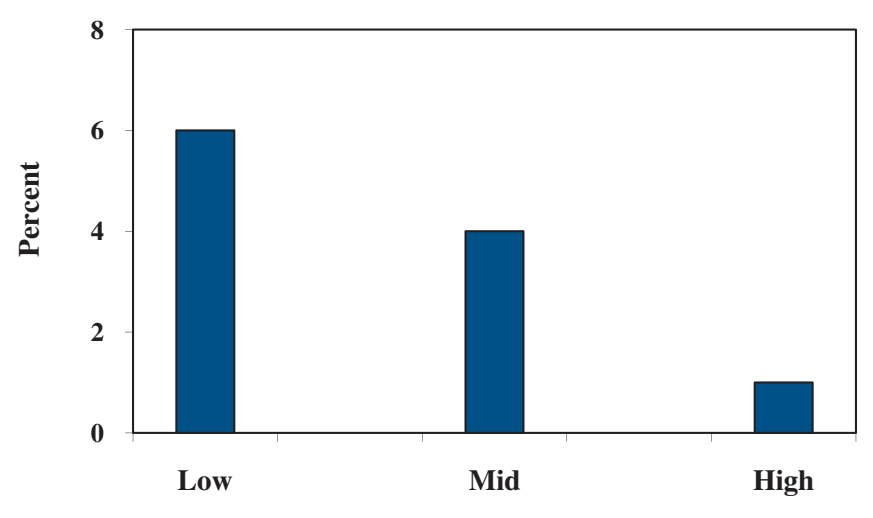

Social Connectedness

Source: Hallman and Roca 2011

norms. Creating safer communities requires engagement with men and boys and community members to complement girls' programs. The Population Council and its partners have worked with boys and men in Brazil, Ethiopia, and India on issues of masculinity and gender inequality and have demonstrated the impact of behavioral programs on reducing self-reported violence perpetrated by men and boys (Erulkar and Alemayehu 2009; Pulerwitz and Barker 2008; Verma et al. 2006). The Council's Addis Birhan project in the Amhara region of Ethiopia engages men in community conversations about dysfunctional gender norms and their toll and costs to women and children. This program has produced positive changes in men's behaviors and attitudes toward masculinity, as reported by men and their young wives (Erulkar and Alemayehu 2009). We plan to build on these initiatives with men and boys to extend the concept of safe spaces to safe communities and relationships.

\section{Making communities safe}

Our experience in working with men and boys has shown promising results and is line with several studies that have begun to demonstrate the feasibility and effectiveness of changing gender norms and reducing SGBV through community-level interventions (Barker et al. 2010). The central approach in these programs is to engage men and boys in conversations about their masculinity, analyze associated problems, and propose acceptable change. The key is to apply a positive rather than a punitive model of behavior change with men and boys, identifying the ways in which such change is in their best interest. The Council will continue to focus on behavior change programs for men and boys that demonstrate positive gender norms while creating a supportive environment for adopting these norms. Similarly, strategies to prevent community-level violence could advance behavior change programs for girls that promote acceptance of confident and assertive behaviors by girls while empowering them to adopt these behaviors. 


\section{References and Resources}

Amin, Sajeda. 2007. "Empowering adolescent girls in rural Bangladesh: Kishori Abhijan." New York: Population Council.

Amin, Sajeda and Luciana Suran (2005). Program efforts to delay marriage through improved opportunities: some evidence from rural Bangladesh, Paper presented at XXV International Population Conference of the International Union for the Scientific Study of Population conference, Tours, France, July 18-23, 2005. Accessed May 3, 2011: http://iussp2005.princeton.edu/ download. aspx?submissionld $=52255$

Austrian, Karen. 2011. "Expanding Safe Spaces, Financial Education, and Savings for Adolescent Girls in Kenya" Promoting Healthy, Safe, and Productive Transitions to Adulthood Brief no. 29. New York, NY: Population Council.

Austrian, Karen and Dennitah Ghati. 2010. Girl Centered Program Design: A Toolkit to Develop, Strengthen and Expand Adolescent Girls Programs. Population Council.

Barker, Gary, Christine Ricardo, Marcos Nascimento, Adepeju Olukoya, et al. 2010. Questioning gender norms with men to improve health outcomes: Evidence of impact. Global Public Health 5(5): 539 - 553

Chong Erica, Kelly Hallman, and Martha Brady. 2006. "Investing when it counts: Generating the evidence base for policies and programmes for very young adolescents--Guide and tool kit." New York, NY: Population Council.

Erulkar, Annabel S. and Awraris Alemayehu. 2009. "Addis Birhan ('New Light'): Fostering husbands' involvement and support in Amhara Region, Ethiopia," Ethiopia Program Brief Series Ethiopia: Population Council.

Erulkar, Annabel S. and James K. Matheka. 2007. "Adolescence in the Kibera slums of Nairobi." Nairobi, Kenya: Population Council.

Hallman, Kelly, Kasthuri Govender, Eva Roca, Rob Pattman, Emmanual Mbatha, and Deevia Bhana. 2011. "Enhancing financial literacy, HIV/AIDS skills, and safe social spaces among vulnerable South African youth," Promoting Healthy, Safe, and Productive Transitions to Adulthood Brief no. 4. New York: Population Council.

Hallman, K and Eva Roca. 2011. "Reducing the social exclusion of girls," Promoting Healthy, Safe, and Productive Transitions to Adulthood Brief no. 27. New York, NY: Population Council.

Heise, Lori, Mary C. Ellsberg, and M. Gottmoeller. 2002. A global overview of gender-based violence. International Journal of Gynecology and Obstetrics 78 Suppl. 1 (2002) S5-S14.

Kenworthy, Nora, Kelly Hallman, and Judith A. Diers. 2008. "Identifying sources of adolescent exclusion due to violence: Participatory mapping in South Africa," Promoting Healthy, Safe, and Productive Transitions to Adulthood Brief no. 30. New York, NY: Population Council.
Jewkes, Rachel, Yandisa Sikweyiya, Robert Morrell, and Kristen Dunkle. 2009. "Understanding Men's health and Use of Violence: Interface of Rape and HIV in South Africa," Gender and Health Research Unit Report. Pretoria: South African Medical Research Council.

Jewkes, Rachel, Loveday Penn-Kekana, and Hetty Rose-Junius. 2005. "If they rape me, I can't blame them": Reflections on gender in the social context of child rape in South Africa and Namibia." Social Science \& Medicine 61:1809-1820.

Jewkes Rachel and Naeema Abrahams. 2002. The epidemiology of rape and sexual coercion in South Africa: an overview. Soc Sci Med. Oct;55(7):123144.

Keesbury, Jill and lan Askew. 2010. "Comprehensive responses to gender-based violence in low-resource settings: Lessons learned from implementation." New York, NY: Population Council.

Koss, Mary P., Lori Heise, and Nancy F.Russo. 1994. The Global Health Burden of Rape. Psychology of Women Quarterly, 18: 509-537.

Levine, Ruth, Cynthia B. Lloyd, Margaret Greene, and Caren Grown. 2009. "Girls Count: A Global Investment \& Action Agenda." Washington, D.C.: Center for Global Development.

Mensch, Barbara, Judith Bruce, and Margaret Greene. 1998. "The Uncharted Passage: Girls' Adolescence in the Developing World." New York, NY: Population Council.

Population Council. 2008. "Africa regional sexual and gender-based violence network consultation: Technical exchange and planning meeting." New York, NY: Population Council.

Pulerwitz, Julie and Gary Barker. 2008. Measuring attitudes toward gender norms among young men in Brazil: Development and psychometric evaluation of the GEM scale. Men and Masculinities 10(3): 322-338.

Verma, Ravi K., Julie Pulerwitz, Vaishali Mahendra, Sujata Khandekar, Gary Barker, P. Fulpagare, and S.K. Singh. 2006. Challenging and Changing Gender Attitudes among Young Men in Mumbai, India. Reproductive Health Matters, 14(28): 135-143.

Wood, Katherine and Rachel Jewkes. 2001. "'Dangerous' love: Reflections on violence among Xhosa township youth," in R. Morrell (ed.), Changing men in Southern Africa. Pietermaritzburg: University of Natal Press.

World Health Organization. 2005. WHO multi-country study on women's health and domestic violence against women: summary report of initial results on prevalence, health outcomes and women's responses. Geneva, World Health Organization.

\section{Population Council}

The Population Council changes the way the world thinks about critical health and development issues. We seek to understand the causes and consequences of gender inequality and the disparities in opportunity that arise during adolescence. We provide the evidence for better on-theground programs and policies that ensure successful and productive transitions to adulthood in developing countries. www.popcouncil.org

(c) 2011 The Population Council, Inc. 